\title{
Intrauterine and Postnatal Exposure to Tobacco and Wood Smoke on Hypothalamic Development and Cognition: An Integrative Review of the Literature
}

\author{
Exposición Intrauterina y Postnatal al Humo de Tabaco y de Leña en el Desarrollo \\ Hipotalámico y la Cognición: Una Revisión Integrativa de la Literatura
}

Ana Maripangui \& Paulo Salinas

\begin{abstract}
MARIPANGUI, A. \& SALINAS, P. Intrauterine and postnatal exposure to tobacco and wood smoke on hypothalamic development and cognition: an integrative review of the literature. Int. J. Morphol., 39(3):773-779, 2021.

SUMMARY: Exposure to air pollution and its pollutants has been associated with important effects on human health since the first years of life, thus it has been seen that exposure to tobacco smoke and wood smoke is directly related to cardiovascular and pulmonary diseases, respiratory and cancers. However, exposure to air pollution during fetal development and its effects on brain structure and function during early childhood and adolescence have been little studied. In this review we have analyzed the literature on prenatal exposure to tobacco and wood smoke and its relationship with hypothalamic development and cognition in the first years of life.The molecular, morphological and physiological aspects of the relationship between pre- and postnatal exposure to tobacco and wood smoke with neural developmental, cognitive and behavioral problems during early childhood and adolescence have not yet been fully clarified. The information available in the scientific literature based on antecedents obtained from epidemiological studies has been negatively affected by confounding variables and great methodological challenges that make it impossible to affirm an exact causal relationship with certainty.
\end{abstract}

KEY WORDS: Tobacco smoke; Wood smoke; Air pollution; Hypothalamic development; Cognition.

\section{INTRODUCTION}

Exposure to air pollution (AP) during fetal development and its effects on brain structure and function during early childhood and adolescence have been little studied. Currently, there is information that suggests that exposure to environmental pollutants, such as tobacco smoke (TS) and wood smoke (WS), have adverse health effects from the first years of life, which suggests an association between both types of smokes with a high prevalence of cardiovascular, pulmonary, respiratory diseases and cancers. Although, antecedents related to brain functions with TS and WS are scarce, there are reports in newborn, children and adolescents (Slotkin, 2004; Polanska et al., 2017; Luk et al., 2018). Koning et al. (2014) suggest that exposure to WS represents a risk to public health similar to the risk of TS. In this sense, it has been reported that although the composition of TS and WS differ in components, there are also some that are present in both and have been associated with a decrease in cognitive functions. Then arises, and given that the world population is exposed to high levels of AP, the need to establish relationships between exposure to AP, TS and WS, with its possible effects on the structure and brain function. The aim of this review is to analyze the literature that highlights the general aspects of the relationships that have been established between prenatal exposure to TS and WS with the development of the hypothalamus and cognitive aspects in childhood and adolescence.

AP and health risks. After COVID-19, AP is the most urgent environmental health risk facing the world's population. According to the World Health Organization (2018a,b), it is the cause of death for seven million people worldwide each year. Boman et al. (2003) estimate that indoor AP in developing countries is responsible for nearly two million excess deaths annually, caused for example by chronic obstructive pulmonary disease, tuberculosis, acute respiratory disease, and cancer. In addition, it states that more than $80 \%$ of the world's population lives in urban 
areas exposed to air quality levels that exceed the limits compatible with health. The World Health Organization (2018a) declared that in addition to outdoor AP, indoor smoke poses a serious health risk to some 3 billion people. Worldwide, $41 \%$ of the population is exposed to AP from polluted domestic air resulting from cooking with polluting fuels and technologies, stating that 4.3 million deaths were attributable to indoor AP (World Health Organization, 2018a). Studies have revealed a link between exposure to indoor and outdoor AP and cardiovascular disease, cancer and respiratory diseases (World Health Organization, 2018b). It was established that the cause of these diseases is mainly due to particulate matter found in polluted air, which can be found associated with TS and WS. Boman et al. estimate that indoor AP in developing countries is responsible for nearly two million excess deaths annually, caused for example by chronic obstructive pulmonary disease, tuberculosis, acute respiratory disease and cancer.

Intrauterine and postnatal exposure. Particulate matter in the air is a complex mixture of solid and liquid particles of primary and secondary origin, which contain a wide range of organic and inorganic components (Tan et al., 2013). From a health perspective, particles are defined by size, the smallest, such as those with an aerodynamic diameter <2.5 microns (PM2.5), have greater impacts on health, these are the main particles present in the smoke of firewood and cigar (Tan et al.). TS is considered one of the main important pollutants of the indoor and outdoor air. Its physiological and molecular effects in adult humans and the development of cancer have been well described. In contrast, how TS affects embryonic development remains poorly understood. Morphological studies of the fetuses of smoking pregnant women have shown various physical deformities induced by constant fetal exposure to tobacco components, especially nicotine. In addition, nicotine exposure decreases fetal body weight and bone/ cartilage growth in addition to decreasing cranial diameter and tibia length. Unfortunately, the molecular pathways leading to these morphological anomalies are not completely understood (Feltes et al., 2013). There is a difference between smoke that is directly consumed by the smoker, known as first-hand smoke and second-hand smoke (SHS). Drope et al. (2018) established that the risks of active smoking include kidney failure, intestinal ischemia and hypertensive heart disease and that even the damage caused by cigarette smoking begins during intrauterine life, since pregnant women who smoke give birth infants at increased risk for congenital disorders, cancer, lung disease, and sudden death. In other hand, prolonged inhalation of WS in high concentrations, induces mild inflammatory effects in the airways, systemic inflammation, and decreased lung function in juvenile and adult mice and rats. Consequently, epidemiological studies have strongly associated exposure to WS with an increase in mortality and morbidity, most notably related to respiratory (asthma and COPD) and cardiovascular (through the pathways of cardiovascular, inflammatory and oxidative stress), however, they have not yet been confirmed in experimental or exposition studies (Sigsgaard et al., 2015; Cascio, 2018; Sun et al., 2019; Environmental Protection Agency, 2020). Prenatal exposure to SHS has been shown to be the leading preventable cause of sudden infant death syndrome and low birth weight. Also, it has been linked to increased incidence of lower-respiratory tract infections, preterm births, otitis media, and dental caries. Exposure to SHS has also been correlated with increased incidence of food insecurity and the metabolic syndrome in children (Rosenthal \& Weitzman, 2011). It has been shown in both animal and human models that nicotine and cotinine (a metabolite of nicotine) freely cross the placenta and accumulate in fetal tissue (Koren, 1995; Lambers \& Clark, 1996; Jauniaux et al., 1999a,b; Matta et al., 2007; Maritz, 2008). Likewise, SHS contains more than 7,000 toxic substances, which include hydrogen cyanide, carbon monoxide, butane, ammonia, toluene, arsenic, lead, chromium, cadmium, polycyclic aromatic hydrocarbons $(\mathrm{PAH})$, tobacco-specific N-nitrosamines, aldehydes, metals and organic compounds, these substances are transported through PM2.5 microparticles in the air (Rosenthal \& Weitzman). Exposure to SHS has been associated with numerous adverse health effects, particularly with increased risk of cancer and heart disease even among children and unborn babies (Drope et al.). Herrmann et al. (2008) established that prenatal and postnatal exposure to SHS has shown a strong association with high rates of behavioral disorders during childhood and adolescence, such as irritability, challenging or oppositional behavior, and attention deficit hyperactivity disorder.

On the other hand, the effects of biomass burning smoke have been studied and reported, both in mothers (Kadam et al., 2013; Wylie et al., 2014; Scott \& Reilly, 2019; Borchers-Arriagada et al., 2020), children (Calderón-Garcidueñas et al., 2008) and fetuses (Fullerton et al., 2008; Sreeramareddy et al., 2011; Trieu et al., 2020; Salinas et al., 2020a,b). Indoor AP, including that due to wood combustion, presents a severe health risk to those exposed (World Health Organization, 2018a). In developed countries, WS encompasses various emission sources, such as the combustion of wood for cooking, burning of wood for intra-residential heating or that from forest fires due to global warming. There is also a considerable contribution from residential wood combustion to outdoor AP, particularly in developed countries, that contributes significantly to human health risks (Schwartz et al., 2020). 
Among these, the smoke whose main source of emission is the combustion of residential wood is considered in countries of the southern (Chile and Argentina) and northern hemisphere (Canada) as one of the main sources of localAP, even displacing the index of AP produced by the combustion of oil derived from motor vehicles and industries. WS, caused by the burning of residential wood, is a mixture of volatile and particulate substances made up of organic and inorganic elements, among its main components are carbon monoxide, nitrogen dioxide, particulate matter (Junemann \& Legarreta, 2007), free radicals and polycyclic aromatic hydrocarbons (Unosson et al., 2013). Evidence of the effect of WS on the development of the fetus or on behavioral aspects of children and adolescents obtained from experimental studies or direct exposure is scarce.

Hypothalamic development impairments. The structure and function of the brain are established from the first years of life in processes that are extremely sensitive to external influences. Thus, during prenatal development, the brain is more susceptible to the negative effects of environmental toxins (Polanska et al.; Rivas et al., 2019). These external influences (Fig. 1) have repercussions by inducing changes in normal neurodevelopment, such as reduced psychomotor functions and an increased risk of behavioral disturbances (Polanska et al.). The hypothalamus is one of the oldest and smallest portions of the brain (Saper \& Lowell, 2014). It is composed of heterogeneous nuclei that control different physiological functions (Gao \& Sun, 2017), such as diet, sleep-wake cycles, body temperature, sexual behaviors, reproduction, responses to stress, and circadian rhythm. (Gao \& Sun), among the most important. This structure is characterized by a plethora of nuclei and territories arranged in a mosaic pattern that interact to regulate behavior (Burbridge et al., 2016). The hypothalamus produces neurotransmitters such as 5hydroxytryptamine, dopamine, glutamate, gamma aminobutyric acid (GABA), as well as various neuropeptides and hormones that contribute to the regulation of basic physiological functions. The development of the hypothalamus, derived from the precordal mesoderm, begins early in embryogenesis and is a complex series of events that includes the establishment of the hypothalamic regional territory, the specification of the subdivision of regional territories, the differentiation and neuronal migration and the formation of sub-nuclei (Gao \& Sun). The rostral part of the hypothalamus contains key integrative circuits for thermoregulation, fever, electrolyte balance, wake-sleep, circadian rhythms, and sexual behavior. The tuberal hypothalamus contains circuits for sexual behavior, aggressiveness, and autonomic and endocrine responses. The posterior region of the hypothalamus plays a role in

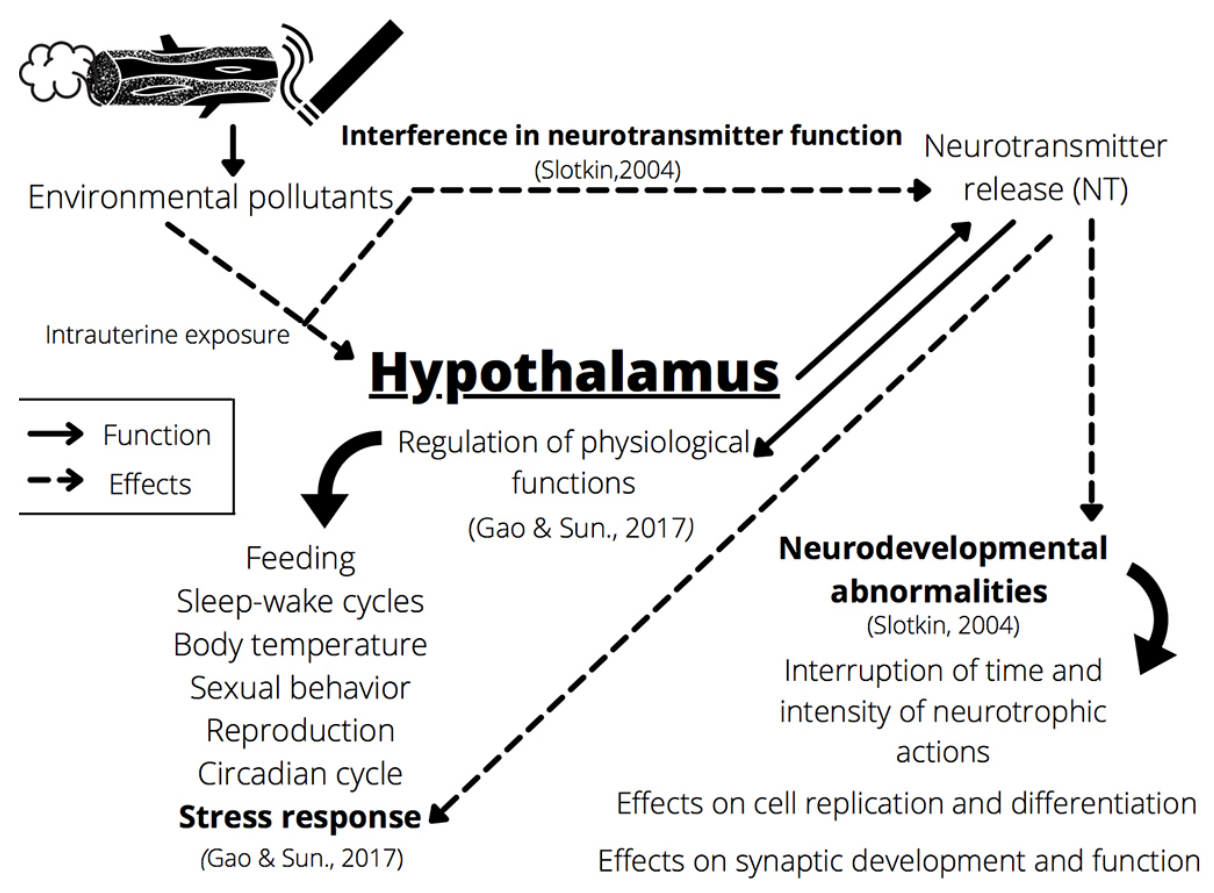

Fig. 1. Synthesis of the effects of intrauterine and postnatal exposure to cigarette and wood smoke on hypothalamic development. 
the regulation of wakefulness and stress responses (Saper \& Lowell). There are reports that demonstrate the relationship between intrauterine exposure to TS and some conditions to specific regions of the brain (Rosenthal \& Weitzman). Rivkin et al. (2008) reported that intrauterine exposure to TS is related to a reduced head circumference, a reduction in cortical gray matter and also in total parenchymal volumes at school age. Decreased brain growth in utero is associated with an increased risk of cognitive difficulties during early childhood (Rosenthal \& Weitzman). In turn, Slotkin establishes that environmental toxins interfere with the different functions of neurotransmitters, generating abnormalities in neurological development by interrupting the time or intensity of neurotrophic actions; and that, among environmental toxins, exposure to TS has long-term adverse effects on specific processes involved in the replication and differentiation of brain cells, the development and function of synaptic.

Cognitive Impairments. The mental functions present in the human being, which allow them to relate to their environment and have knowledge of their own inner world, have been grouped into 3 large groups: affective (emotions, motivation and feelings), psychomotor (related to psychomotor skills and motor systems), and cognitive ones, which include attention, orientation, perception, memory, thought and language. Portella (2016) has described the main cognitive functions, defining learning as the process by which new information or knowledge is acquired, and establishing that from a physiological point of view it is characterized as a set of plastic changes in the effectiveness of transmission synaptic of the medial and inferior temporal wolves including the amygdala and hippocampus. Memory constitutes the process by which acquired knowledge is encoded, stored and retrieved. Likewise, Fuster (2008) characterizes the executive functions, defining them as the set of cognitive abilities that allow the anticipation and establishment of goals, the formation of plans and programs, the initiation of activities and mental operations, the self-regulation of tasks and the ability to carry them out efficiently, considering their main components: working memory, inhibitory control, planning, monitoring, categorization and cognitive flexibility. Both describe attention, as the fundamental cognitive function that allows filtering irrelevant sensory information and processing relevant information; and finally, they establish language as the cognitive function that allows to express experiences and communicate them through the use of symbols, signals and sounds registered by the sense organs. Cognitive functions depend on interactions between multiple neural systems that use a

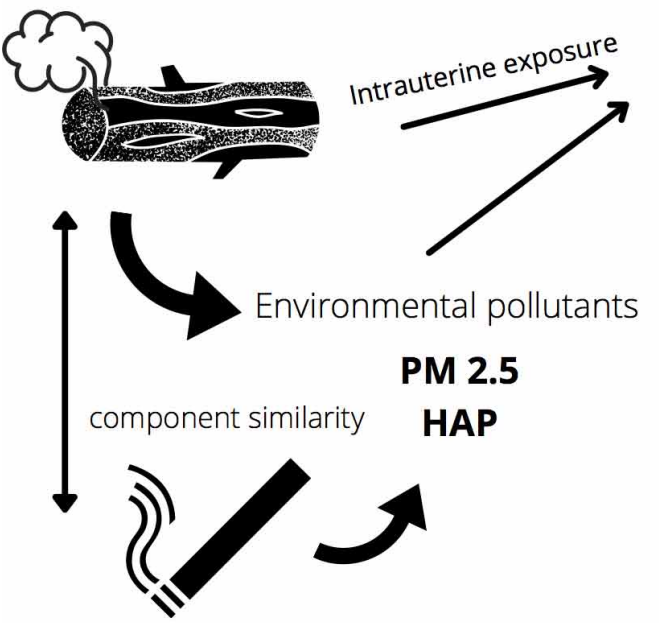

Negative effects on stress response

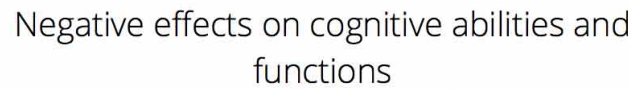

e.g (Rivas et al., 2019; Polanska et al., 2017; Perera et al., 2011)

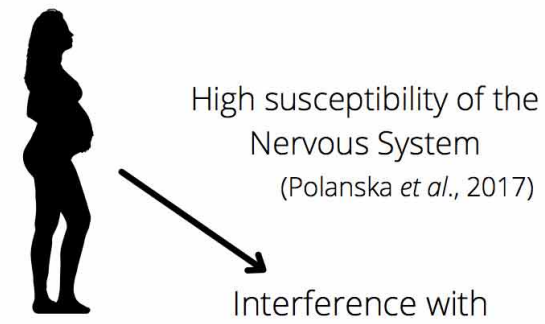

neurotransmitter function (Slotkin, 2004)

Neurodevelopmental abnormalities (Slotkin, 2004)

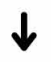
childhood and adolescence

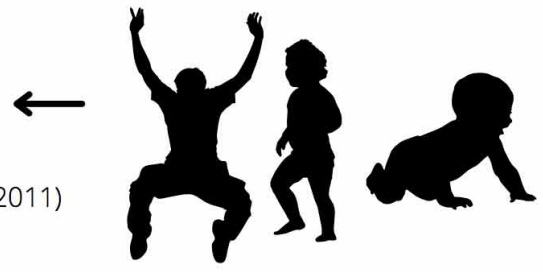

Fig. 2. Synthesis of the effects of intrauterine and postnatal exposure to cigarette and wood smoke on stress and cognitive abilities during childhood and adolescence. 
variety of neurotransmitters, such as the cholinergic system (mediated by acetylcholine, which is important in processes such as learning, memory, neural development and in the reward system ), the gabaminergic system (mediated by GABA, which mainly fulfills an inhibitory function that exerts a control on memory processes), the dopamienergic system (mediated by dopamine, which has implications on cognition, motivation, reward responses and plays an important role in specific synaptic changes in learning and memory), the noradrenergic system (mediated by norepinephrine, which is related to functions based on the alert system), and the serotonergic (mediated by serotonin) and glutamatergic systems (mediated by glutamate, which are involved in learning and memory processes). Rivas et al. reported an association between exposure to AP during gestation with reduced psychomotor development, autism spectrum disorder and impacts on cognitive development. In addition, they showed that prenatal exposure and during the first years of life to TS has a negative association with fundamental cognitive skills in children between 7-10 years old, such as: working memory and attention, and they also reproduce a reduced memory working memory and an association with reduced performance of the conflict network, one of the functional networks of attention, which had already been previously reported by Slotkin. Recent studies highlight that passive smoking during pregnancy could affect the fetus in the future with respect to behavioral development, and in particular aggressive and externalizing behaviors. Different studies have associated the effects of prenatal exposure to TS with a decrease in neurological development, including cognitive, language and motor skills, during the first two years of life (Polanska et al.) and with behavior problems, hyperactivity and inattention (Luk et al.). In turn, Perera et al. (2012) established an association between prenatal exposure to $\mathrm{PAH}$, another component of TS and WS, with a decrease in cognitive functions, and found that a high prenatal exposure to $\mathrm{PAH}$, in combination with high levels of exposure SHS is associated with a reduction in intellectual capacity (IQ) levels at the age of 5 years (Fig. 2).

Perspectives. Although the evidence recognizes the existence of PAH in WS, there are still no robust studies that provide conclusive evidence that may associate secondary effects in neurodevelopment. We hypothesize regarding a probable effect of WS on the development of the central nervous system and its a posteriori effects mainly due to the antecedents obtained in studies of cigarette smoke, given the fraction of similar components between both types of smoke. The effects of exposure to WS have been associated mainly with respiratory and lung diseases, cancers and also with cardiovascular diseases, and although these have been well described, its effects on the aspects of hypothalamic development, stress response and cognition. According to the literature consulted in this review, they have not been the focus of extensive research in recent years. Information on the effects of intrauterine exposure to WS in these aspects is limited. However, two lines of research derive from the reviewed literature: (1) it has been established that environmental toxins interfere with the functions of neurotransmitters (Slotkin; Gao \& Sun; Polanska et al.), given that the hypothalamus regulates physiological functions, such as the response to stress through the synthesis of neurotransmitters, it is possible to hypothesize regarding the probable role of intrauterine exposure to WS in high concentrations to WS , particularly in the early stages of the development of the nervous system and (2) intrauterine exposure to TS has been associated with negative effects on cognition, such as learning, behavior and attention problems (Slotkin; Polanska et al.; Luk et $a l$.), and in turn. An important association has been reported in the composition of TS and WS, since both present carbon monoxide, particulate matter (PM2.5) and PAH, likewise, it has been reported that prenatal exposure to PM2.5 and PAH is negatively associated with cognitive abilities such as working memory and attention (Perera et al.; Rivas et al.). Finally, it is possible to hypothesize regarding intrauterine exposure to WS and given the similarity of its components to TS, it may have the same significance in different cognitive abilities and functions.

\section{CONCLUSION}

The molecular, morphological and physiological aspects of the relationship between pre- and postnatal exposure to TS and WS with neural developmental, cognitive and behavioral problems during early childhood and adolescence have not yet been fully clarified. The information available in the scientific literature based on epidemiological studies has been negatively affected by confounding variables and great methodological challenges that make it impossible to affirm a causal relationship with certainty. A positive and outstanding aspect is the use of animal models, and the consequent reduction of confounding variables, that have provided causal antecedents that would help to understand and demonstrate the probable deleterious effect on the neurological and cognitive development of those who were exposed to WT or SW during intrauterine life. The only certainty is that fetuses and children who were exposed to high concentrations of ST and/or SW for a long time during intrauterine and postnatal life are at a disadvantage in relation to their cognitive and behavioral abilities during adolescence. 
FUNDING. This research was funded by Fondecyt-ANID, Chile (Fondecyt Grant $\mathrm{N}^{\circ} 11200775$ ) and Pontificia Universidad Católica de Valparaíso(DI 039.472/2020).

MARIPANGUI, A. \& SALINAS, P. Exposición intrauterina y postnatal al humo de tabaco y de leña en el desarrollo hipotalámico y la cognición: una revisión integrativa de la literatura. Int. J. Morphol., 39(3):773-779, 2021.

RESUMEN: La exposición a la contaminación del aire se ha asociado con importantes efectos en la salud humana desde los primeros años de vida. Estudios han demostrado con certeza que la exposición al humo de tabaco y humo de leña está directamente relacionada con enfermedades cardiovasculares, pulmonares, respiratorias y cánceres. Sin embargo, la exposición a la contaminación del aire durante el desarrollo fetal y sus efectos a posteriori sobre la estructura y función del cerebro durante la primera infancia y la adolescencia son aún desconocidos. En esta revisión analizamos la literatura sobre la exposición prenatal al tabaco y al humo de leña y su relación con el desarrollo hipotalámico y la cognición en los primeros años de vida. Los aspectos moleculares, morfológicos y fisiológicos de la asociación entre la exposición pre y postnatal al humo de tabaco o al humo de leña con problemas del desarrollo neurológico normal, cognitivos y de comportamiento durante la primera infancia y la adolescencia aún no se han aclarado completamente. La información disponible en la literatura científica basada en antecedentes obtenidos de estudios epidemiológicos ha sido afectada negativamente por variables de confusión y grandes desafíos metodológicos que hacen imposible afirmar una relación directa y causal exacta con certeza.

PALABRAS ClAVE: Humo de tabaco; Humo de madera; Contaminación del aire; Desarrollo hipotalámico; Cognición.

\section{REFERENCES}

Boman, B. C.; Forsberg, A. B. \& Järvholm, B. G. Adverse health effects from ambient air pollution in relation to residential wood combustion in modern society. Scand. J. Work Environ. Health, 29(4):251-60, 2003.

Borchers-Arriagada, N.; Palmer, A. J.; Bowman, D. M.; Williamson, G. J. \& Johnston, F. H. Health Impacts of Ambient Biomass Smoke in Tasmania, Australia. Int. J. Environ. Res. Public Health, 17(9):3264, 2020.

Burbridge, S.; Stewart, I. \& Placzek, M. Development of the neuroendocrine hypothalamus. Compr. Physiol., 6(2):623-43, 2016.

Calderón-Garcidueñas, L.; Mora-Tiscareño, A.; Ontiveros, E.; GómezGarza, G.; Barragán-Mejía, G.; Broadway, J.; Chapman, S.; Valencia-Salazar, G.; Jewells, V.; Maronpot, R. R. et al. Air pollution, cognitive deficits and brain abnormalities: a pilot study with children and dogs. Brain Cogn., 68(2):117-27, 2008.

Cascio, W. Wildland fire smoke and human health. Sci. Total Environ., 624:586-95, 2018.
Drope, J.; Schluger, N.; Cahn, Z.; Drope, J.; Hamill, S.; Islami, F.; Liber, A.; Nargis, N. \& Stoklosa, M. The Tobacco Atlas. Atlanta, American Cancer Society and Vital Strategies, 2018.

Environmental Protection Agency (EPA). National Annual Emissions Trend. Washington (D.C.), Environmental Protection Agency, 2020. Available from: https://www.epa.gov/sites/production/files/2018-04/ national_tier1_caps.xlsx

Feltes, B. C.; Poloni, J. F; Notari, D. L. \& Bonatto, D. Toxicological effects of the different substances in tobacco smoke on human embryonic development by a systems chemo-biology approach. PLoS One, 8(4):e61743, 2013.

Fullerton, D. G.; Bruce, N. \& Gordon, S. B. Indoor air pollution from biomass fuel smoke is a major health concern in the developing world. Trans. R. Soc. Trop. Med. Hyg., 102(9):843-51, 2008

Fuster, J. M. The Prefrontal Cortex. $4^{\text {th }}$ ed. Boston, Academic Press, 2008.

Gao, Y. \& Sun, T. Molecular regulation of hypothalamic development and physiological functions. Physiol. Behav., 176(1):139-48, 2017.

Herrmann, M., King, K. \& Weitzman, M. Prenatal tobacco smoke and postnatal secondhand smoke exposure and child neurodevelopment. Curr. Opin. Pediatr., 20(2):184-90, 2008.

Jauniaux, E.; Gulbis, B.; Acharya, G. \& Gerlo, E. Fetal amino acid and enzyme levels with maternal smoking. Obstet. Gynecol., 9(3):480-1, 1999a.

Jauniaux, E.; Gulbis, B.; Acharya, G.; Thiry, P. \& Rodeck, C. Maternal tobacco exposure and cotinine levels in fetal fluids in the first half of pregnancy. Obstet. Gynecol., 93(1):25-9, 1999b.

Junemann, A. \& Legarreta, G. Inhalación de humo de leña: una causa relevantepero poco reconocida de Enfermedad Pulmonar Obstructiva Crónica. Rev. Am. Med. Respir., 7(2):21-57, 2007.

Kadam, Y. R.; Mimansa, A.; Chavan, P. V. \& Gore, A. D. Effect of prenatal exposure to kitchen fuel on birth weight. Indian J. Community Med., 38(4):212-6, 2013

Koning, H. W. de.; Smith, K. R. \& Last, J. M. Biomass fuel combustion and health. Int. Appl. Mech., 50(5):575-81, 2014.

Koren, G. Fetal toxicology of environmental tobacco smoke. Curr. Opin. Pediatr., 7(2):128-31, 1995.

Lambers, D. S. \& Clark, K. E. The maternal and fetal physiologic effects of nicotine. Semin. Perinatol., 20(2):115-26, 1996.

Luk, T. T.; Wang, M. P.; Suen, Y. N.; Koh, D. S.; Lam, T. H. \& Chan, S. S. Early childhood exposure to secondhand smoke and behavioural problems in preschoolers. Sci Rep., 8(1):15434, 2018.

Maritz, G. S. Nicotine and lung development. Birth Defects Res. CEmbryo Today, 84(1):45-53, 2008.

Matta, S. G.; Balfour, D. J.; Benowitz, N. L.; Boyd, R. T.; Buccafusco, J. J.; Caggiula, A. R.; Craig, C. R.; Collins, A. C.; Damaj, M. I.; Donny, E. C.; et al. Guidelines on nicotine dose selection for in vivo research. Psychopharmacology (Berl.), 190(3):269-319, 2007.

Perera, F.; Li, T. Y.; Lin, C. \& Tang, D. Effects of prenatal polycyclic aromatic hydrocarbon exposure and environmental tobacco smoke on child IQ in a Chinese cohort. Environ. Res., 114:40-6, 2012.

Polanska, K.; Krol, A.; Merecz-Kot, D.; Ligocka, D.; Mikolajewska, K.; Mirabella, F.; Chiarotti, F.; Calamandrei, G. \& Hanke, W. Environmental tobacco smoke exposure during pregnancy and child neurodevelopment. Int. J. Environ. Res., 14(7):796, 2017.

Portella, M. J. Circuitos neuronales de la cognición. Psiquiatr. Biol., 23(Suppl. 1):16-22, 2016

Rivas, I.; Basagaña, X.; Cirach, M.; López-Vicente, M.; Suades-González, E.; Garcia-Esteban, R.; Álvarez-Pedrerol, M.; Dadvand, P. \& Sunyer, J. Association between early life exposure to air pollution and working memory and attention. Environ. Health Perspect., 127(5):57002, 2019.

Rivkin, M. J.; Davis, P. E.; Lemaster, J. L.; Cabral, H. J.; Warfield, S. K.; Mulkern, R. V.; Robson, C. D.; Rose-Jacobs, R. \& Frank, D. A. Volumetric MRI study of brain in children with intrauterine exposure to cocaine, alcohol, tobacco, and marijuana. Pediatrics, 121(4):74150, 2008. 
Rosenthal, D. G., \& Weitzman, M. Examining the effects of intrauterine and postnatal exposure to tobacco smoke on childhood cognitive and behavioral development. Int. J. Ment. Health, 40(1):39-64, 2011.

Salinas, P.; Veuthey, C.; Bruna, N.; Bongiorno, A. \& Romero, I. Impact of maternal exposure to wood smoke pollution on fetal lung morphology in a rat model. Int. J. Morphol., 38(5):1250-7, 2020a.

Salinas, P.; Veuthey, C.; Rubio, I.; Bongiorno, A. \& Romero, I. Exposure to wood smoke pollution during pre-gestational period of rat has effects on placenta volume and fetus size. Int. J. Morphol., 38(5):1356$64,2020 b$.

Saper, C. B. \& Lowell, B. B. The hypothalamus. Curr. Biol., 24(23):R1111-6, 2014

Schwartz, C.; Bølling, A. K. \& Carlsten, C. Controlled human exposures to wood smoke: a synthesis of the evidence. Part. Fibre Toxicol., 17:49, 2020.

Scott, A. F. \& Reilly, C. A. Wood and biomass smoke: addressing human health risks and exposures. Chem. Res. Toxicol., 32(2):219-21, 2019.

Sigsgaard, T.; Forsberg, B.; Annesi-Maesano, I.; Blomberg, A.; Bølling, A.; Boman, C.; Bønlokke, J.; Brauer, M.; Bruce, N.; Heroux, M. E.; et al. Health impacts of anthropogenic biomass burning in the developed world. Eur. Respir. J., 46(6):1577-88, 2015.

Slotkin, T. A. Cholinergic systems in brain development and disruption by neurotoxicants: Nicotine, environmental tobacco smoke, organophosphates. Toxicol. Appl. Pharmacol., 198(2):132-51, 2004.

Sreeramareddy, C. T.; Shidhaye, R. R. \& Sathiakumar, N. Association between biomass fuel use and maternal report of child size at birth-an analysis of 2005-06 India Demographic Health Survey data. BMC Public Health, 27(11):403, 2011.

Sun, Q.; Miao, C.; Hanel, M.; Borthwick, A. G. L.; Duan, Q.; Ji, D. \& Li, H. Global heat stress on health, wildfires, and agricultural crops under different levels of climate warming. Environ. Int., 128:125-36, 2019.

Tan, Y.; Yang, R.; Zhao, J.; Cao, Z.; Chen, Y.; Mao, X.; Zeng, A.; Hu, T.; Zhou, J. et al. The associations between air pollution and adverse pregnancy outcomes in China he relationships between various components of air. Environ. Sci. Technol., 47(21):181-214, 2013.

Trieu, J.; Yao, J.; McLean, K. E.; Stieb, D. M. \& Henderson, S. B. Evaluating an Air Quality Health Index (AQHI) amendment for communities impacted by residential woodsmoke in British Columbia, Canada. J. Air Waste Manag. Assoc., 70(10):1009-21, 2020.

Unosson, J.; Blomberg, A.; Sandström, T.; Muala, A.; Boman, C.; Nyström, R.; Westerholm, R.; Mills, N. L.; Newby, D. E.; Langrish, J. P.; et al. Exposure to wood smoke increases arterial stiffness and decreases heart rate variability in humans. Part. Fibre Toxicol., 10:20, 2013.

World Health Organization (WHO). Burden of Disease From The Joint Effects Of Household And Ambient Air Pollution for 2016. Summary of Results. Geneva, World Health Organization, 2018a. Available from: http://apps.who.int/gho/data/node.sdg

World Health Organization (WHO). Exposure to Household Air Pollution for 2016. Geneva, World Health Organization, 2018b

Wylie, B. J.; Coull, B. A.; Hamer, D. H.; Singh, M. P.; Jack, D.; YeboahAntwi, K.; Sabin, L.; Singh, N. \& MacLeod, W. B. Impact of biomass fuels on pregnancy outcomes in central East India. Environ. Health, 13(1):1, 2014.

\author{
Corresponding author: \\ Paulo Salinas \\ Laboratory of Animal \& Experimental Morphology \\ Institute of Biology \\ Pontificia Universidad Católica de Valparaíso \\ Valparaíso \\ CHILE
}

E-mail: paulo.salinas@pucv.cl

ORCID ID: https://orcid.org/0000-0003-2273-0904

Received: 27-01-2021

Accepted: 21-03-2021 